\title{
Czy napromienianie części piersi powinno się stać standardowym elementem oszczędzającego leczenia chorych na wczesnego raka piersi? Głos na nie
}

\author{
Anna Niwińska
}

\author{
Is accelerated partial breast irradiation (APBI) the standard? Vote for NO
}

\section{Kilka ważnych zagadnień na wstępie}

APBI (Accelerated Partial Breast Irradiation) ma niewątpliwe zalety w postaci skrócenia całkowitego czasu leczenia i skrócenia kolejek oczekujących na rozpoczęcie terapii w zakładach radioterapii, dlatego społeczność onkologiczna z niecierpliwością oczekuje chwili, kiedy ta metoda stanie się standardem postępowania u chorych na wczesnego raka piersi.

Dlaczego, mimo ponad dwudziestoletniej tradycji, APBI wciąż nie można uznać za standard postępowania? Odpowiedzią jest po części sama definicja standardu medycznego. Standardem medycznym, opracowywanym zwykle przez towarzystwa naukowe i zespoły ekspertów w formie zbioru zaleceń, są schematy postępowania zgodne z zasadami medycyny opartej na faktach (Evidence-Based Medicine - EBM), a najsilniejszymi dowodami naukowymi są wyniki badań klinicznych randomizowanych. Dlatego decyzja o uznaniu APBI za standard powinna być ustalona na podstawie wyników badań z losowym doborem chorych, niezależnie od liczby i wyników badań bez randomizacji.

W badaniach klinicznych randomizowanych technikę APBI porównuje się z konwencjonalnym napromienianiem na całą pierś. Aby nowe techniki APBI uznać za standardowe, należy udowodnić, że odsetek wznów jest nie wyższy niż przy standardowym napromienianiu. Jednocześnie trzeba pamiętać, że wyniki konwencjonalnego leczenia oszczędzającego raka piersi uległy w ostatnich latach znaczącej poprawie. Pierwotnie odsetek wznów po leczeniu oszczędzającym, po 5 latach obserwacji, wynosił 8,8-10\% [1, 2].
Obecnie odsetek wznów wynosi 0,4-2\% [3-5] i ta wartość ma stanowić odnośnik przy ocenie skuteczności APBI. Zatem ryzyko nawrotu po 5 latach u chorych leczonych według nowych technik APBI nie powinno przekraczać $2 \%$, aby uznać je za standardowe.

Ponadto badania kilku ostatnich lat wskazują, że przed podjęciem decyzji o uznaniu APBI za standard postępowania należy przeanalizować skuteczność i bezpieczeństwo tej metody u chorych na raka piersi w różnym wieku oraz w obrębie poszczególnych podtypów biologicznych, gdyż odsetki niepowodzeń w znaczący sposób zależą od tych czynników. Odsetek wznów po leczeniu oszczędzającym jest najniższy u osób starszych oraz w podtypie raka luminalnego A (HER2(-) ER/PR(+) [5].

W końcu należy pamiętać, że APBI jest nowym sposobem radioterapii, zatem wymaga oceny odczynów wczesnych po krótkim czasie od zakończenia leczenia i odczynów późnych po wielu latach. Specyfika APBI w postaci nienapromieniania znaczącej części piersi niesie za sobą zwiększone ryzyko wznów poza lożą po guzie pierwotnym oraz nowych raków w piersi leczonej, dlatego w ocenie tej metody niezbędny jest długi czas obserwacji.

Czy w świetle tych rozważań istnieje dziś wystarczająca liczba dowodów naukowych, aby uznać APBI za standard postępowania? Najbardziej przekonywające byłyby wyniki badań randomizowanych z długim czasem obserwacji, z odsetkiem wznów po 5 latach ok. 2-3\%, ze szczegółowymi danymi na temat ryzyka nawrotu w poszczególnych grupach wiekowych i podtypach biologicznych raka.

Klinika Nowotworów Piersi i Chirurgii Rekonstrukcyjnej

Centrum Onkologii — Instytut im. Marii Skłodowskiej-Curie w Warszawie

Wystąpienie podczas I Konferencji Naukowej czasopisma Nowotwory „Debaty onkologiczne” 5-6 kwietnia 2013 roku 


\section{Wyniki badań nad APBI bez randomizacji}

Brachyterapia śródtkankowa, której tradycja sięga ponad 20 lat, polega na napromienianiu loży po guzie z marginesem 1-2 cm za pomocą źródeł promieniowania umieszczonych w kilku, kilkunastu prowadnicach. Dawka promieniowania z użyciem źródeł o niskiej mocy dawki LDR (Low Dose Rate) wynosi 50Gy w czasie 4,5 dnia, natomiast z użyciem źródeł o wysokiej mocy dawki HDR (High Dose Rate) wynosi 32 Gy ( 8 × Gy) lub 34 Gy $(10$ × 3,4 Gy) w czasie 4,5-5 dni. Leczenie promieniami przeprowadza się po wygojeniu loży po operacji i uzyskaniu wyniku badania histopatologicznego. Odsetek wznów miejscowych po czasie obserwacji 5-11 lat wynosi od 0\% do 15\%, w większości badań jest to odsetek 2,9-4,7\% [6-15].

Brachyterapia śródjamowa z użyciem aplikatorów balonowych MammoSite i Contura oraz hybrydowych Savi polega na napromienianiu loży 1-8 źródłami o wysokiej mocy dawki promieniowania. Czas obserwacji chorych po brachyterapii śródjamowej typu MammoSite jest znacznie krótszy niż po tradycyjnej brachyterapii śródtkankowej z użyciem wielu aplikatorów i wynosi 1-4 lat, a odsetek wznów miejscowych mieści się w granicach 0-5\% [16-24]. W największym z badań (Mammosite Registry Trial), obejmującym 1449 chorych, odsetek wznów miejscowych po 5 latach wynosił 3,6\% [25].

Teleradioterapia przeprowadzana techniką konformalną 3D lub techniką IMRT (Intensity Modulated Radiation Therapy) jest metodą stosowaną najkrócej, jednocześnie jest ona najbardziej dostępna sprzętowo. Odsetek wznów po czasie obserwacji 1-4 lat wynosi 0-6\% [26, 27], z różnym efektem kosmetycznym po IMRT [28, 29].

Metody śródoperacyjne, czyli napromienianie pojedynczą frakcją na sali operacyjnej, tuż po wykonaniu zabiegu operacyjnego. Można wykonać napromienianie promieniami RTG o energii 50 kV w dawce 20 Gy na powierzchni kulistego aplikatora, 5-7 Gy w odległości 1 cm (aparat Intrabeam) lub elektronami o indywidualnie dobranej energii w zakresie 4-12 MeV, w dawce 20-21 Gy (aparat Novac-7 lub Mobetron). W badaniu ELIOT analizowano grupę 1822 chorych. Po czasie obserwacji 4 lat odsetek wznów wynosił $2,3 \%$ [30], a według ostatnio przedstawianych danych na Konferencji w St. Gallen w 2013 roku — 6\% [31].

\section{Wyniki badań randomizowanych}

Obecnie wartość poszczególnych technik APBI jest oceniana w kilkunastu badaniach klinicznych randomizowanych, jednakże dotychczas znamy wyniki wstępne tylko 5 z nich.

Najstarszym badaniem randomizowanym jest badanie angielskie, w którym odsetek wznów po APBI z pól zewnętrznych w stosunku do napromieniania konwencjonalnego był nie do zaakceptowania (odpowiednio 15\% vs 11\%) [32]. W kolejnym badaniu angielskim odsetek wznów był również wyższy po APBI z pól zewnętrznych w stosunku do konwencjonalnej teleradioterapii (12\% vs 4\%) [33].

W badaniu węgierskim, przeprowadzonym w latach 1998-2007, oceniano wartość brachyterapii śródtkankowej u 258 chorych. W badaniu tym odsetek wznów po 5 latach po APBI wyniósł $4,7 \%$, a po konwencjonalnej radioterapii - 3,4\% [34]. Po 10 latach obserwacji odsetki wynosiły odpowiednio 5,1\% i 5,7\% ( $p=0,77)$ [35]. Ograniczeniem tego badania jest mała grupa chorych (kolejne chore spełniające kryteria włączenia do APBI były rekrutowane przez autorów do innego badania klinicznego).

Kolejnym badaniem z randomizacją było badanie TARGIT A, którego wyniki zostały opublikowane w 2010 r. [36] i uaktualnione na Konferencji w San Antonio w 2012 roku [37]. W grupie 3451 chorych przydzielanych do losowo napromieniania 1 frakcją 20 Gy promieniami rtg o energii 50 kV lub do ramienia kontrolnego napromienianiem standardowym na całą pierś, po czasie obserwacji 2 lat i 5 miesięcy w ramieniu badanym stwierdzono 3,3\% wznów w piersi w porównaniu z 1,3\% w ramieniu kontrolnym $(p=0,04)$. Zaobserwowano też statystycznie większą liczbę wznów lokoregionalnych i przerzutów odległych w ramieniu z APBI $(p=0,02)[37]$.

W badaniu randomizowanym ELIOT testowano radioterapię śródoperacyjną elektronami w 1 frakcji 20 Gy (501 chorych) i porównywano wyniki z napromienianiem konwencjonalnym na pierś (515 chorych). Po raz pierwszy wyniki tego badania przedstawiono na Konferencji w St. Gallen 2013 [31]. Po 5 latach obserwacji w grupie leczonej metodą APBI stwierdzono znamiennie więcej wznów miejscowych i nowych raków w piersi leczonej w porównaniu z grupą kontrolną, w której stosowano standardową radioterapię na całą pierś (odpowiednio 5,3\% vs 0,7\%, p < 0,001). Przeżycia całkowite były w obu grupach porównywalne $(p=0,69)$.

Najwięcej komentarzy i nadziei wiąże się z badaniem NSABP-B39, w którym porównuje się 3 techniki APBI (brachyterapię śródtkankową, brachyterapię śródjamową i teleradioterapię) z napromienianiem konwencjonalnym z pól zewnętrznych na całą pierś. W badaniu tym biorą udział także chore z wysokim ryzykiem nawrotu (wiek > 18 r.ż., przerzuty do pachowych węzłów chłonnych, rak przedinwazyjny). W planie jest rekrutacja 4300 chorych. Wielu ekspertów jest zdania, że wyniki tego badania będą decydujące dla uznania techniki APBI za standard. Niestety, będą one dostępne dopiero za kilka lat. Oczekuje się także wyników następujących badań klinicznych randomizowanych: RAPID/Ontario Clinical Group, GEC-ESTRO, Import-LOW, IRMA, SHARE, RTOG 0413 i innych [38].

Czy wyniki dotychczas opublikowanych badań randomizowanych są satysfakcjonujące i usprawiedliwiają bezwarunkowe wdrożenie APBI do praktyki klinicznej? Obiektywnie wyższe odsetki wznów w ramionach z APBI w porównaniu z napromienianiem standardowym na całą 
pierś oraz wyższe odsetki wznów po uaktualnianiu danych po dłuższym czasie obserwacji (TARGIT, ELIOT) sugerują, że dziś jeszcze należy być ostrożnym w uznaniu APBI za standard i poczekać kilka lat na ostateczne dane.

\section{Co robić do czasu opublikowania wyników badań randomizowanych?}

Tymczasem, bez względu na brak ostatecznych danych, APBI jest metodą coraz częściej stosowaną na świecie [39], chociaż z nie najlepszym skutkiem. Na podstawie analizy 92735 chorych na raka piersi w wieku ponad 67 lat, leczonych w latach 2003-2007 (u 6952 przeprowadzono brachyterapię, u 85783 standardowe napromienianie całej piersi), po 5 latach obserwacji w grupie APBI stwierdzono statystycznie znamiennie więcej wznów wymagających mastektomii (4\% vs 2\%), więcej powikłań nieinfekcyjnych, bólów piersi, martwic tłuszczowych i złamań żeber, jednak bez wpływu na przeżycie [40].

Dlaczego wyniki leczenia metodą APBI są nieco gorsze od oczekiwanych? Wydaje się, że najważniejszym czynnikiem decydującym o wynikach leczenia APBI jest niewłaściwy dobór chorych. Znacząca część pacjentek, u których doszło do wznów, była obarczona czynnikami wysokiego ryzyka nawrotu, dlatego nigdy nie powinna być kwalifikowana do tej metody. Aby zaradzić temu problemowi, w 2009 roku, na podstawie ówcześnie dostępnych wyników badań, wydano rekomendacje ASTRO [41] i — niezależnie — GEC-ESTRO [42] precyzujące, które osoby można leczyć techniką APBI poza badaniami klinicznymi (grupa niskiego ryzyka wznowy, suitable group według ASTRO), u których takie leczenie jest wątpliwe, i dlatego APBI powinno być stosowane tylko w ramach badań klinicznych (cautionary group według ASTRO), oraz u których chorych APBI jest przeciwwskazane z uwagi na wysokie ryzyko wznowy (unsuitable group według ASTRO). Amerykańskie Towarzystwo Brachyterapii (ABS) również wydało swoje wskazania do APBI [43]. Niestety, wśród analizowanych czynników nie uwzględniono stopnia ekspresji receptora HER2, stopnia histologicznej złośliwości, aktywności proliferacyjnej raka, a tym samym — nie uwzględniono podtypów biologicznych raka piersi. W efekcie analizy z 2012 roku, mające na celu ustalenie wartości klasyfikacj ASTRO i GEC-ESTRO, wykazały ich ograniczoną wartość prognostyczną [44-46]. Jakkolwiek w grupie, w której dopuszcza się wykonywanie APBI poza badaniami klinicznymi, odsetek wznów był niski, nie obserwowano gradacji ryzyka wznów w dwóch pozostałych grupach. Stanowi to potwierdzenie, że na podstawie rekomendacji ASTRO i GEC-ESTRO przy ocenie stopnia ryzyka wznowy przed kwalifikacją do APBI brakuje istotnych czynników biologicznych, które mogłyby dokładniej określić ryzyko nawrotu i bezpieczeństwo zastosowania techniki APBI w indywidualnym przypadku. Powyższe wątpliwości zostały zauważone przez autorów badania ELIOT [30]. W badaniu tym wykazano, że ryzyko nawrotu po APBI zależy od podtypu biologicznego raka piersi. Podtyp luminalny A powoduje najmniejsze ryzyko nawrotów miejscowych i odległych. Najwięcej wznów miejscowych stwierdza się w grupie raków HER2 dodatnich, najwięcej drugich raków w piersi leczonej oraz najkrótsze przeżycie obserwuje się w raku receptorowo trójujemnym [30]. Badacze udowodnili, że najlepsze wyniki stosowania APBI uzyskuje się u chorych z guzem $<1 \mathrm{~cm}$, w stopniu złośliwości histologicznej G1, z niskim indeksem proliferacyjnym i podtypem luminalnym A [31].

Obecnie uważa się, że do czasu opublikowania wyników badań randomizowanych (5-7 lat), należy stosować APBI wyłącznie u chorych z grupy niskiego ryzyka (suitable group według ASTRO) [38, 46, 47]. Trzeba przedyskutować z chorą zalety i wady APBI, poinformować, że nie są znane wyniki odległe, w tym powikłania późne po radioterapii, i uzyskać pisemną zgodę od chorej. Jednocześnie lekarze stosujący APBI powinni śledzić piśmiennictwo dotyczące tego leczenia, gdyż obecnie obowiązujące rekomendacje ASTRO i GEC-ESTRO nie są ostateczne i będą modyfikowane po publikowaniu kolejnych badań.

Poza doborem chorych istnieje wiele innych wątpliwości odnośnie bezpieczeństwa stosowania APBI. Często poszczególne techniki APBI są mało porównywalne z uwagi na różnice w objętości napromienianej, w homogenności dawki i w dawce na skórę. Istnieją różnice w wielkości marginesów tkanek zdrowych, schematów dawkowania (dawka-czas leczenia), zwłaszcza że na podstawie modelu liniowo-kwadratowego nie można wyliczyć wiarygodnej dawki biologicznej dla pojedynczej frakcji 20 Gy czy 21 Gy. Istnieje także problem dawki na narządy zdrowe (druga pierś, płuco, serce), a w przypadku technik śródoperacyjnych - problem wiarygodnej oceny histologicznej marginesu tkanek zdrowych wokół raka w preparacie mrożonym. Problemem jest także konieczność podwyższenia dawki na całą pierś po napromienianiu 1 frakcją 21 Gy w przypadkach, gdy otrzymany po tygodniach wynik badania histopatologicznego wskazuje na wysokie ryzyko wznowy miejscowej. Dlatego w napromienianiu śródoperacyjnym rozważa się badanie NMR piersi przed rozpoczęciem leczenia w celu precyzyjnego określenia rozległości nowotworu [38, 47]. Pozostaje mieć nadzieję, że wszystkie te wątpliwości zostaną rozwiane po uzyskaniu wyników toczących się obecnie badań randomizowanych, to jest po 2017 roku.

\section{Uwagi końcowe}

Dostępne badania nie dostarczają wystarczających danych, aby można było uznać APBI za standard postępowania we wczesnym raku piersi. Metoda ta nadal pozostaje $w$ fazie eksperymentu, gdyż nie są znane wyniki wszystkich ważnych badań randomizowanych, a wyniki kilku dotychczas opublikowanych budzą wątpliwości z powodu zbyt wysokiego odsetka wznów i zbyt krótkiego czasu obserwacji. 
Największą niepewność budzi wciąż dobór chorych do APBI. Pozostaje mieć nadzieję, że toczące się obecnie badania randomizowane rozwiążą tę wątpliwość, i za kilka lat zostanie sprecyzowana grupa pacjentek z wczesnym rakiem piersi, u których APBI będzie standardem leczenia.

Tymczasem, biorąc pod uwagę niewątpliwe zalety APBI, w oczekiwaniu na wyniki ważnych badań klinicznych randomizowanych dopuszcza się stosowanie tej metody poza badaniami klinicznymi w grupie niskiego ryzyka według kryteriów ASTRO (grupa suitable), w ramach badań własnych, za zgodą lokalnej komisji bioetycznej. Należy jednak pamiętać, że nawet w grupie niskiego ryzyka wymagana jest ostrożność w doborze chorych pod względem wieku i podtypu biologicznego raka piersi.

\section{Dr hab. n. med. Anna Niwińska}

Klinika Nowotworów Piersi i Chirurgii Rekonstrukcyjnej

Centrum Onkologii — Instytut im. Marii Skłodowskiej-Curie

ul. Roentgena 5, 02-781Warszawa

e-mail:annaniwinska@gmail.com

\section{Piśmiennictwo}

1. Fisher B, Anderson B, Redmond C i wsp. Reanalysis and Results after 12 Years of Follow-up in a Randomized Clinical Trial Comparing Total Mastectomy with Lumpectomy with or without Irradiation in the Treatment of Breast Cancer. N Engl J Med 1995; 333: 1456-1461.

2. Veronesi U, Luini A, Del Vecchio M i WSP. Radiotherapy after breast-preserving surgery in women with localized cancer of the breast. $N$ Engl J Med 1993; 328: 1587-1591.

3. Hughes KS, Schnaper LA, Bellon JR i wsp. Lumpectomy Plus Tamoxifen With or Without Irradiation in Women Age 70 Years or Older With Early Breast Cancer: Long-Term Follow-Up of CALGB 9343. J Clin Oncol 2013 May 20. doi: 10.1200/ JCO.2012.48.3875.

4. Blamey RW, Bates T, Chetty U i wsp. Radiotherapy or tamoxifen after conserving surgery for breast cancers of excellent prognosis: British Association of Surgical Oncology (BASO) II trial. Eur J Cancer 2013; 49: 2294-2302. doi: 10.1016/j.ejca.2013.02.031.

5. Arvold ND, Taghian AG, Niemierko A i wsp. Age, breast cancer subtype approximation, and local recurrence after breast-conserving therapy. J Clin Oncol 2011; 29: 3885-3891.

6. Kaufman SA, DiPetrillo TA, PriceLL i wsp. Long-term outcome and toxicity in a Phase I/II trial using high-dose-rate multicatheter interstitial brachytherapy for T1/2 breast cancer. Brachytherapy 2007; 6: 286-292.

7. Patel RR, Christensen ME, Hodge CW i wsp. Clinical outcome analysis in "high-risk" versus "low-risk" patients eligible for national surgical adjuvant breast and bowel B-39/radiation therapy oncology group 0413 trial: five-year results. Int J Radiat Oncol Biol Phys 2008; 70: 970-973.

8. Gomez-Iturriaga, Pina AL, Cambeiro M i wsp. Early breast cancer treated with conservative surgery, adjuvant chemotherapy, and delayed accelerated partial breast irradiation with high-dose-rate brachytherapy. Brachytherapy 2008; 7: 310-315.

9. White JR, Winter KA, Kuske RA i wsp..Long-term outcome from RTOG 9517: A phase I/II study of accelerated partial breast irradiation (APBI) with multicatheter brachytherapy (MCT) following lumpectomy for early-stage breast cancer. J Clin Oncol 2012; 30: 147.

10. Johansson B, Karlsson L, Liljegren G i wsp. Pulsed dose rate brachytherapy as the sole adjuvant radiotherapy after breast-conserving surgery of T1-2 breast cancer: First long time results from a clinical study. Radiother Oncol 2009; 90: 30-35.

11. Yoshida K, Nose T, Masuda N i wsp. Preliminary result of accelerated partial breast irradiation after breast-conserving surgery. Breast Cancer 2009; 16: 105-112.

12. Polgar C, Major T, Fodor J. Accelerated partial-breast irradiation using high-dose-rate interstitial brachytherapy: 12-year update of a prospective clinical study. Radiother Oncol 2010; 94: 274-279.

13. Hattangadi JA, Powell SN, Macdonald SM i wsp. Accelerated partial breast irradiation with low-dose-rate interstitial implant brachytherapy after wide local excision: 12-year outcomes from a prospective trial. Int J Radiat Oncol Biol Phys 2012; 83: 791-800.
14. Strnad V, Hildebrandt G, Potter R i wsp. Accelerated partial breast irradiation: 5-year results of the German-Austrian multicenter phase II trial using interstitial multicatheter brachytherapy alone after breast-conserving surgery. Int J Radiat Oncol Biol Phys 2011; 80: 17-24.

15. Shah C, Antonucci JV, Wilkinson JB i wsp. Twelve-year clinical outcomes and patterns of failure with accelerated partial breast irradiation versus whole-breast irradiation: Results of a matched-pair analysis. Radiother Oncol 2011; 100: 210-214.

16. Richards GM, Berson AM, Rescigno J i wsp. Acute toxicity of high-dose-rate intracavitary brachytherapy with the MammoSite applicator in patients with early-stage breast cancer. Ann Surg Oncol 2004; 11: 739-746.

17. Tsai PI, Ryan M, Meek K i wsp. Accelerated partial breast irradiation using the MammoSite device: early technical experience and short-term clinical follow-up. Am Surg 2006; 72: 929-934.

18. Niehoff P, Ballardini B, Polgar Ci iwsp. Early European experience with the MammoSite radiation therapy system for partial breast brachytherapy following breast conservation operation in low-risk breast cancer. Breast 2006; 15: 319-325.

19. Niehoff P, Polgar C, Ostertag H. i wsp. Clinical experience with the MammoSite radiation therapy system for brachytherapy of breast cancer: Results from an international phase II trial. Radiother Oncol 2006; 79: 316-320.

20. Benitez PR, Keisch ME, Vicini F i wsp.Five-year results: The initial clinical trial of MammoSite balloon brachytherapy for partial breast irradiation in early-stage breast cancer. Am J Surg 2007; 194: 456-462.

21. Chao KK, Vicini FA, Wallace M i wsp. Analysis of treatment efficacy, cosmesis, and toxicity using the MammoSite breast brachytherapy catheter to deliver accelerated partial-breast irradiation: The William Beaumont Hospital experience. Int J Radiat Oncol Biol Phys 2007; 69: 32-40.

22. Cuttino LW, Keisch M, Jenrette JM i wsp. Multi-institutional experience using the MammoSite radiation therapy system in the treatment of early-stage breast cancer: 2-year results. Int J Radiat Oncol Biol Phys 2008; 71: 107-114.

23. Vicini F, Beitsch P, Quiet C i wsp. Five-year analysis of treatment efficacy and cosmesis by the American Society of Breast Surgeons MammoSite Breast Brachytherapy Registry Trial in patients treated with accelerated partial breast irradiation. Int J Radiat Oncol Biol Phys 2011; 79: 808-817.

24. Vicini FA, Keisch $M$, Shah C i wsp.Factors associated with optimal long-term cosmetic results in patients treated with accelerated partial breast irradiation using balloon-based brachytherapy. Int J Radiat Oncol Biol Phys 2012; 83: 512-518.

25. Beitsch PD, Wilkinson JB, Vicini F. Tumor bed control with balloon-based accelerated partial breast irradiation: incidence of true recurrences versus elsewhere failures in the American Society of Breast Surgery MammoSite( $\left.{ }^{\circledR}\right)$ Registry Trial. Ann Surg Oncol 2012; 19: 3165-3170. doi: 10.1245/s10434-012-2489-x.

26. Leonard C, Carter D, Kercher J. i wsp. Prospective trial of accelerated partial breast intensity-modulated radiotherapy. Int J Radiat Oncol Biol Phys 2007; 67: 1291-1298.

27. Vicini $F$, Winter K, Wong J i wsp. Initial efficacy results of RTOG 0319: Three-dimensional conformal radiation therapy (3D-CRT) confined to the region of the lumpectomy cavity for stage I/II breast carcinoma. Int J Radiat Oncol Biol Phys 2010; 77: 1120-1127.

28. Hepel JT, Tokita M, MacAusland SG i wsp. Toxicity of three-dimensional conformal radiotherapy for accelerated partial breast irradiation. Int J Radiat Oncol Biol Phys 2009; 75: 1290-1296.

29. Jagsi R, Ben-David MA, Moran JM i wsp. Unacceptable cosmesis in a protocol investigating intensity-modulated radiotherapy with active breathing control for accelerated partial-breast irradiation. Int J Radiat Oncol Biol Phys 2010; 76: 71-78.

30. Veronesi U, Orecchia R, Luini A i wsp. Intraoperative radiotherapy Turing Brest conserving burgery: a study on 1,822 cases treated with electrons. Breast Cancer Res Treat 2010; 124: 141-151.

31. Orecchia R. Partial breast irradiation: Targeting volume or breast molecular subtypes? StGallen Breast Cancer Conference Primary Therapy of Early Breast Cancer 2013. Prezentacja ustna na Sesji 8: Areas of controversy and newer radiation approaches, numer abstraktu: SP8.03.

32. Ribeiro GG, Magee B, Swindell R i wsp. The Christie Hospital breast conservation trial: An update at 8 years from inception. Clin Oncol 1993; 5: 278-283.

33. Dodwell DJ, Dyker K, Brown J i wsp. A randomised study of whole-breast vs tumour-bed irradiation after local excision and axillary dissection for early breast cancer. Clin Oncol 2005; 17: 618-622.

34. Polgar C, Fodor J, Major T i wsp. Breast-conserving treatment with partial or whole breast irradiation for low-risk invasive breast carcinoma -5 -year results of a randomized trial. Int J Radiat Oncol Biol Phys 2007; 69: 694-702. 
35. Polgar C, Fodor J, Major T i wsp. Breast-conserving therapy with partial or whole breast irradiation: Ten-year results of the Budapest randomized trial. Radiother Oncol 2013 doi: 10.1016/j.radonc.2013.05.008.

36. Vaidya JS, Joseph DJ, Tobias JS i wsp. Targeted intraoperative radiotherapy versus whole breast radiotherapy for breast cancer (TARGIT-A trial): an international, prospective, randomised non-inferiority phase 3 trial. Lancet 2010; 376: 91-102.

37. Vaidya JS i wsp. Targeted intraoperative radiotherapy for early breast cancer: Targit-A trial- updated analysis of local recurrence and first analysis of survival. Cancer Res 2012; 72 (24 Suppl.): S4-2.

38. Moser EC, Vrieling C. Accelerated partial breast irradiation: the need for well-defined patient selection criteria, improved volume definitions, close follow-up and discussion of salvage treatment. The Breast 2012; 21: 707-715.

39. Abbott AM, Habermann EB, Tuttle TM. Trends in the use of implantable accelerated partial breast irradiation therapy for early stage breast cancer in the united states. Cancer 2011; 117: 3305-3310.

40. Smith GL, Xu Y, Buchholz TA, Giordano SH i wsp. Association between treatment with brachytherapy vs whole-breast irradiation and subsequent mastectomy, complications, and survival among older women with invasive breast cancer. JAMA 2012; 307: 1827-1837.

41. Smith BD, Arthur DW, Buchholz TA i wsp. Accelerated partial breast irradiation consensus statement from the American Society for Radiation Oncology (ASTRO). Int J Radiat Oncol Biol Phys 2009; 74: 987-1001.
42. Polgar C, Van Limbergen E, Potter R i wsp. Patient selection for accelerated partial-breast irradiation (APBI) after breast-conserving surgery: Recommendations of the Groupe Europeen de Curietherapie-European Society for Therapeutic Radiology and Oncology (GGEC-ESTRO) breast cancer working group based on clinical evidence (2009). Radioth Oncol 2010; 94: 264-273.

43. Shah C, Vicini F, Wazer DE i wsp. The American Brachytherapy Society consensus statement for accelerated partial breast irradiation. Brachytherapy 2013; 12: 267-277.

44. Wilkinson JB, Beitsch PD, Shah C i wsp. Evaluation of current consensus statement recommendations for accelerated partial breast irradiation: a poled analysis of Wiliam Beaumont Hospital and American Society of Breast Surgeon MammoSite Registry Trial Data. Int J Radiat Oncol Biol Phys 2013; 85: 1179-1185.

45. Leonardi CL, Maisonneuve P, Mastropasqua MG i wsp. Accelerated partial breast irradiation with intraoperative electrons: using GEC-ESTRO recommendations as guidance for patients selection. Radiother Oncol 2013; 106: 21-27.

46. Vicini F, Arthur D, Wazer D i wsp. Limitations of the American Society of Therapeutic Radiology and Oncology Consensus Panel Guidelines on the use of accelerated partial breast irradiation. Int J Radiat Oncol Biol Phys 2011; 79: 977-984.

47. Orecchia R, Leonardo MC. Intraoperative radiation therapy: is it a standard now? The Breast 2011; 20: S111-S115.

W dniu 27 września 2014 r. odbędzie się w Warszawie Konferencja „Radioterapia śródoperacyjna - doświadczenia ośrodków polskich”

\author{
Organizatorzy: \\ Zakład Brachyterapii \\ Klinika Nowotworów Piersi i Chirurgii Rekonstrukcyjnej \\ Zakład Fizyki Medycznej \\ Centrum Onkologii — Instytutu im. Marii Skłodowskiej-Curie w Warszawie
}

Patronat:

Prof. Krzysztof Warzocha — Dyrektor Centrum Onkologii — Instytutu im. Marii Skłodowskiej-Curie

Polskie Towarzystwo Chirurgii Onkologicznej

Polskie Towarzystwo Onkologiczne, Oddział Warszawski

Doświadczenia w stosowaniu radioterapii śródoperacyjnej zaprezentują przedstawiciele ośrodków w: Poznaniu, Lublinie, Szczecinie, Wrocławiu, Gliwicach, Bydgoszczy i Warszawie

\author{
Miejsce: \\ Budynek Profilaktyki Nowotworów \\ Centrum Onkologii — Instytut im. Marii Skłodowskiej-Curie \\ w Warszawie, ul. Roentgena 5 \\ Zgłoszenia: \\ brachyterapia@coi.waw.pl
}

